\title{
Evaluation of wireless determination of skin temperature using iButtons
}

Citation for published version (APA):

van Marken Lichtenbelt, W. D., Daanen, H. A. M., Wouters, L., Fronczek, R., Raymann, R. J., Severens, N. M. W., \& Someren, E. J. W. V. (2006). Evaluation of wireless determination of skin temperature using iButtons. Physiology \& Behavior, 88(4-5), 489-497. https://doi.org/10.1016/j.physbeh.2006.04.026

Document status and date:

Published: 01/01/2006

DOI:

10.1016/j.physbeh.2006.04.026

Document Version:

Publisher's PDF, also known as Version of record

Document license:

Taverne

Please check the document version of this publication:

- A submitted manuscript is the version of the article upon submission and before peer-review. There can be important differences between the submitted version and the official published version of record.

People interested in the research are advised to contact the author for the final version of the publication, or visit the DOI to the publisher's website.

- The final author version and the galley proof are versions of the publication after peer review.

- The final published version features the final layout of the paper including the volume, issue and page numbers.

Link to publication

\footnotetext{
General rights rights.

- You may freely distribute the URL identifying the publication in the public portal. please follow below link for the End User Agreement:

www.umlib.nl/taverne-license

Take down policy

If you believe that this document breaches copyright please contact us at:

repository@maastrichtuniversity.nl

providing details and we will investigate your claim.
}

Copyright and moral rights for the publications made accessible in the public portal are retained by the authors and/or other copyright owners and it is a condition of accessing publications that users recognise and abide by the legal requirements associated with these

- Users may download and print one copy of any publication from the public portal for the purpose of private study or research.

- You may not further distribute the material or use it for any profit-making activity or commercial gain

If the publication is distributed under the terms of Article $25 \mathrm{fa}$ of the Dutch Copyright Act, indicated by the "Taverne" license above, 


\title{
Evaluation of wireless determination of skin temperature using iButtons
}

\author{
Wouter D. van Marken Lichtenbelt ${ }^{\text {a,* }}$, Hein A.M. Daanen ${ }^{\text {b,c }}$, Loek Wouters ${ }^{\text {a }}$, Rolf Fronczek ${ }^{\text {d,e }}$, \\ Roy J.E.M. Raymann ${ }^{d}$, Natascha M.W. Severens ${ }^{f}$, Eus J.W. Van Someren ${ }^{\text {d,g }}$ \\ ${ }^{a}$ Nutrition and Toxicology Institute Maastricht (NUTRIM), Department of Human Biology, Maastricht University, Maastricht, The Netherlands \\ ${ }^{\mathrm{b}}$ TNO Defense, Security and Safety, Soesterberg, The Netherlands \\ ${ }^{c}$ Faculty of Movement Sciences, VU University, Amsterdam, The Netherlands \\ ${ }^{\mathrm{d}}$ Netherlands Institute for Neuroscience, Amsterdam, The Netherlands \\ e Department of Neurology and Clinical Neurophysiology, Leiden University Medical Center, Leiden, The Netherlands \\ ${ }^{\mathrm{f}}$ Department of Energy Technology, Technical University Eindhoven, The Netherlands \\ ${ }^{\mathrm{g}}$ Departments of Neurology, Clinical Neurophysiology and Medical Psychology, VU University Medical Center, Amsterdam, The Netherlands
}

Received 13 December 2005; received in revised form 11 April 2006; accepted 24 April 2006

\begin{abstract}
Measurements of skin temperatures are often complicated because of the use of wired sensors. This is so in field studies, but also holds for many laboratory conditions. This article describes a wireless temperature system for human skin temperature measurements, i.e. the Thermochron iButton DS1291H. The study deals with validation of the iButton and its application on the human skin, and describes clinical and field measurements.

The validation study shows that iButtons have a mean accuracy of $-0.09{ }^{\circ} \mathrm{C}\left(-0.4{ }^{\circ} \mathrm{C}\right.$ at most $)$ with a precision of $0.05{ }^{\circ} \mathrm{C}\left(0.09{ }^{\circ} \mathrm{C}\right.$ at most $)$. These properties can be improved by using calibration.

Due to the size of the device the response time is longer than that of conventional sensors, with a $\tau$ in water of $19 \mathrm{~s}$. On the human skin under transient conditions the response time is significantly longer, revealing momentary deviations with a magnitude of $1{ }^{\circ} \mathrm{C}$.

The use of iButtons has been described in studies on circadian rhythms, sleep and cardiac surgery. With respect to circadian rhythm and sleep research, skin temperature assessment by iButtons is of significant value in laboratory, clinical and home situations. We demonstrate that differences in laboratory and field measurements add to our understanding of thermophysiology under natural living conditions. The advantage of iButtons in surgery research is that they are easy to sterilize and wireless so that they do not hinder the surgical procedure.

In conclusion, the application of iButtons is advantageous for measuring skin temperatures in those situations in which wired instruments are unpractical and fast responses are not required.

(C) 2006 Elsevier Inc. All rights reserved.
\end{abstract}

Keywords: Thermoregulation; Temperature sensor validation; Sleep research; Surgery

\section{Introduction}

Since the human skin forms the interface between the human body and the thermal environment, skin temperature is essential to quantify heat transfer. The temperature distribution over the body's

\footnotetext{
* Corresponding author. Department of Human Biology/NUTRIM, Maastricht University, PO Box 616, 6200 MD, Maastricht, The Netherlands. Tel.: +31 43 3881629; fax: +31 433670976 .

E-mail address: markenlichtenbelt@hb.unimmaas.nl (W.D. van Marken Lichtenbelt).
}

surface provides useful information for many research and clinical applications. For skin temperature measurements the following thermally sensitive methods of measurement are generally applied: thermocouples, thermistors, and infrared sensors.

Thermistors and thermocouples are relatively inexpensive, but these systems have the disadvantage of wires that connect the skin sensor to a measuring device or a data logger that is worn on the body. These wires take time to apply, are prone to breaking, and may hinder the subjects. Some systems use temperature transmitters, in which case the receiver still needs to be worn on the body. 


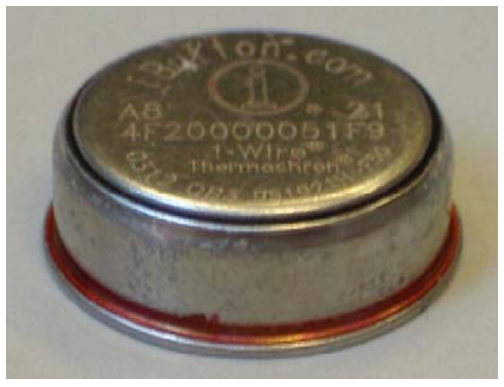

Fig. 1. An iButton.

Here, a wireless temperature system for human skin temperature measurements is described, i.e. the iButton (type DS1921H; Maxim/Dallas Semiconductor Corp., USA; Fig. 1). The iButton is a small $\left(16 \times 6 \mathrm{~mm}^{2}\right)$, rugged self-sufficient system that measures temperature and records the results in a protected memory section. Afterwards time and temperature data can be transferred to a computer for data analysis. Although thermochron iButtons have been used in animal research [1], there are no reports on the extended validation of the device and its application in humans.

The small size and absence of wiring indicate that the iButton may be particularly valuable with regard to the long-term and ambulatory monitoring required for human research on metabolism, sleep and circadian rhythms, nutrition, and sports physiology. Our understanding of human thermal physiology may benefit from the observations during ambulatory monitoring in everyday life. Moreover, wireless skin temperature monitoring facilitates the long-term monitoring of an important part of autonomic regulation in subjects that do not comply well with extensive wiring, e.g. children or subjects with neurodegenerative disorders, such as Alzheimer's dementia or Parkinson's disease.

The value of skin temperature assessment in sleep research is that the endogenous skin warming resulting from increased skin blood flow is functionally linked to sleep propensity. In fact, the gradient between the temperature of the distal and proximal skin may be one of the best physiological correlates of sleep propensity [2]. In metabolic studies core-skin temperature gradients measured with wired thermistors have shown significant correlates with (changes in) metabolism $[3,4]$. Using the iButton combined with core temperature telemetry, these studies can be extended to more natural living conditions.

Thus, the device appears to be a convenient alternative for the conventional thermistors and thermocouples. However, it is unknown whether the measurement accuracy and the response time are appropriate and how they function on the human skin compared to the generally accepted methods.

iButtons are currently being used in animal studies, as we know from symposium presentations [5]. Studies published in journals are rare. To our knowledge, only a few studies mention the use of iButtons [1,6-8].

The aim of this study is to validate the iButton, determine its time response under both physical and physiological conditions, and describe some field and clinical applications.

The article has three sections. The first deals with validation studies, encompassing accuracy measurements, determination of response time, and determination of the spatial sensitivity, i.e. which side of the button is the sensitive part. The second section describes the application on the human skin, comparing the iButton with conventional thermocouples. Finally, the use of iButtons in clinical and field studies is discussed. ${ }^{1}$

\subsection{Description of the iButton and its key features}

The Thermochron iButton ${ }^{\circledR}$ DS1291H (Dallas Maxim) has a semiconductor temperature sensor, a computer chip with a real time clock and memory, and a $3 \mathrm{~V}$ Lithium battery enclosed in a $16 \times 6 \mathrm{~mm}^{2}$ stainless steel can. The sensor is located towards the top of the iButton and the battery towards the bottom. Manufacturing specifications are: a temperature range between +15 and $+46^{\circ} \mathrm{C}$, an accuracy of $1{ }^{\circ} \mathrm{C}$ with a precision of $0.125^{\circ} \mathrm{C}$, provided an eight-bit $\mathrm{AD}$ converter is used. The output value given by the iButton is the instantaneous value at that particular moment. During the measurements the information is stored (NV RAM). It can afterwards be transferred to a personal computer, at a maximum rate of $142 \mathrm{kbps}$. For this purpose, the iButton should be clipped into an adapter connected to the computer.

The iButton has been designed for the human temperature range.

The recording is done at a user-defined rate. Up to 2048 temperature values taken at equidistant intervals ranging from 1 to 255 min can be stored. With 1-min intervals, this results in a maximum measurement period of $34 \mathrm{~h}$.

\section{Validation studies I: iButton properties}

\subsection{Accuracy of the iButton}

The accuracy and precision of the iButton were determined using a water bath and a reference thermometer. Secondly, it was investigated whether a correction formula based on an independent calibration would result in a higher accuracy.

\subsubsection{Materials and methods}

Two experiments were conducted with 30 iButtons. The sampling rate was set at 1-min intervals. The iButtons were loosely placed in a thermostat water bath (MGW Lauda K6, Westbury, NY), in a net with small meshes, together with the tip of a calibrated certified thermometer (Testo 950 with sensor 06280016 , accuracy $0.1 \pm 0.05{ }^{\circ} \mathrm{C}$, Testo, Almere, The Netherlands). There was ample space for the water to flow along the iButtons and the calibration thermometer. The water bath was kept at a constant temperature during plateau measurements, which lasted at least 15 min. Only stable (plateau) temperatures were included in the analysis. Twelve plateau values were used ranging from 18 to $41^{\circ} \mathrm{C}$. The final five 1-min interval measurements of each plateau were averaged and used for statistical analysis. The water bath temperature variation during these measurements was always less than $0.05^{\circ} \mathrm{C}$.

\footnotetext{
1 Statement of interest: None of the authors have any financial or other interest in the companies involved in the production and sales of the test equipment.
} 


\subsubsection{Statistical analysis}

In order to determine the temperature deviation of the individual iButtons, the linear regressions between the values of the standard thermometer and each iButton were calculated. For each iButton the bias (or accuracy) was calculated as the mean of the differences between the temperature of the iButton and that of the standard thermometer, and their standard deviation revealed the error (or precision) [9]. In order to compare the uncorrected and corrected results, the bias of the absolute differences was calculated.

With the same iButtons, linear regression was applied to an independent data set in order to calculate individual correction formulas. The improvement due to the correction formulas was tested with a two-tailed paired $T$-test using the biases of the absolute values.

\subsubsection{Results and discussion}

The linear regressions between the iButtons and the calibrated thermometer were highly significant with Pearson correlation coefficients larger than 0.99 . The mean bias amounted to $-0.09 \pm$ $0.22{ }^{\circ} \mathrm{C}$ (range $=-0.40-0.40{ }^{\circ} \mathrm{C}$ ). The bias of absolute values averaged $0.21 \pm 0.12{ }^{\circ} \mathrm{C}$ (range $=0.05-0.40{ }^{\circ} \mathrm{C}$ ). The error (or precision) averaged $0.05 \pm 0.02{ }^{\circ} \mathrm{C}$ (range $\left.=0.03-0.09{ }^{\circ} \mathrm{C}\right)$. These results show that if calibration is required, this should be carried out for each iButton individually.

An independent calibration was performed to determine a correction formula, based on linear regression, for each iButton. The slope calibration coefficients averaged $1.004 \pm 0.004{ }^{\circ} \mathrm{C}$ (range $=0.992-1.01^{\circ} \mathrm{C}$ ), and the intercept calibration coefficients $0.02 \pm 0.28{ }^{\circ} \mathrm{C}$ (range $\left.=-0.65-0.59{ }^{\circ} \mathrm{C}\right)$. With a correction based on the individual calibration formulas the Pearson correlation coefficients all exceeded 0.999 . The corrected bias averaged $0.05 \pm 0.06{ }^{\circ} \mathrm{C}$ (range $\left.=0.01-0.26^{\circ} \mathrm{C}\right)$, and the corrected bias of the absolute values $0.06 \pm 0.06{ }^{\circ} \mathrm{C}$ (range $=0.02-0.26{ }^{\circ} \mathrm{C}$ ). The mean error was $0.03 \pm 0.01{ }^{\circ} \mathrm{C}$ (range $=0.01-0.05{ }^{\circ} \mathrm{C}$ ). The bias was significantly smaller after correction $(p<0.001$, paired $T$-test on absolute values). The upper values of the bias were observed with two iButtons only. Excluding these iButtons, the remaining 28 revealed a maximum absolute bias of $0.07^{\circ} \mathrm{C}$.

It should be emphasized that after calibration, the bias and error of the iButtons become similar to the accuracy of the reference thermometer itself, i.e. satisfactory for precise measurement. Secondly, since the readout of the iButton is digitized with a resolution of $0.125^{\circ} \mathrm{C}$, improvement after calibration is relevant only when many observations are taken.

\subsection{Response time}

The response time of the iButton is determined by calculating the time constant $(\tau)$ by heating in water. Because the heat capacity and conductivity of water are somewhat higher than those of the human skin and most of the iButton surface is in contact with tape and air, experiments on the human skin have been performed as well (see below). Even though the sampling rate is low (one per minute), model fitting enables determination of the time constant because the output value given by the iButton is the instantaneous value at that moment.

\subsubsection{Materials and methods}

The experimental setup consisted of two water vessels of polystyrene foam filled with water at different temperatures. The water temperature in the vessels was measured with a calibrated certified thermometer (Testo 901). Eight iButtons were loosely placed in an open test tube holder. In this way there was sufficient space between the iButtons so that they were completely surrounded by water. The iButtons were first put in the vessel with $T_{\text {water }}=18.7^{\circ} \mathrm{C}$ and subsequently, immediately after the instantaneous measurement, put in another water vessel with $T_{\text {water }}=41.3{ }^{\circ} \mathrm{C}$. The sample rate was set to one sample per minute.

\subsubsection{Statistical analysis}

The response time of the iButtons in the experiment was estimated by the following equation:

$T(t)=T_{\infty}+\left(T_{0}-T_{\infty}\right) e^{-\frac{t}{\tau}}$

with $t$ the time in s, $T$ the temperature, and the subscripts $\infty$ and 0 denoting the values at infinity and at the start. At $t=\tau$ the process was completed for $63.2 \%$. Eq. (1) was fitted for each individual iButton temperature curve by non-linear least square fitting (MATLAB 6.5).

\subsubsection{Results and discussion}

In Fig. 2 the temperatures as measured with eight iButtons are shown during the switch from cold to warm water at $t=2 \mathrm{~min}$. The plotted marks in the figure are the instantaneous temperatures at that time. Fitting Eq. (1) for each individual temperature curve led to $T_{\infty}=41.1 \pm 0.3{ }^{\circ} \mathrm{C}, T_{0}=18.7 \pm 0.3{ }^{\circ} \mathrm{C}$, and $\tau$ as fitting parameter to a value of $\tau=0.31 \pm 0.06 \mathrm{~min}$, i.e. or $\tau \sim 19$ s.

\subsection{Spatial sensitivity}

The iButton has a top side with smooth edges and a bottom side with a protruding edge. Since the manufacturer does not

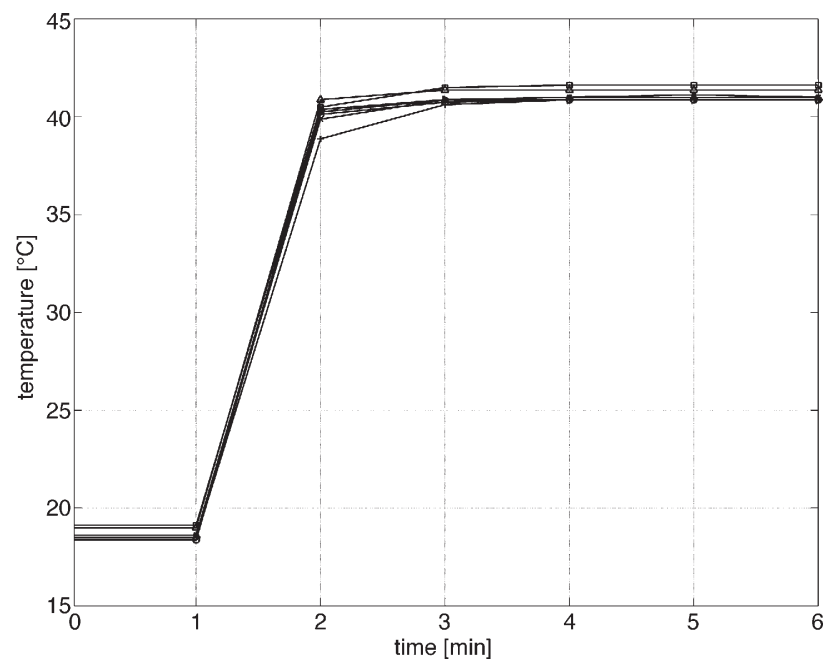

Fig. 2. Temperature of eight iButtons in equilibrium with water at a temperature of $18.7^{\circ} \mathrm{C}$ and after a sudden shift to $41.3{ }^{\circ} \mathrm{C}$ at $t=1 \mathrm{~min}$. 
provide information about which side can best be placed on the surface of interest, an experiment was performed in which the time responses of both sides were compared.

\subsubsection{Materials and methods}

Twelve iButtons were placed on a table to obtain the same starting temperature. Sampling rate was set at 1-min intervals. After 10 min six iButtons were placed top up and six iButtons top down on a hot plate $\left(56.6^{\circ} \mathrm{C}\right) .5 \mathrm{~min}$ later an ice cube big enough to cover all the iButtons was placed on top of them, thereby cooling all iButtons on one side.

\subsubsection{Statistical analysis}

The statistical difference between the temperature of the two sets of iButtons during warming and cooling was tested by means of analysis of variance [10].

\subsubsection{Results and discussion}

The ambient temperature, measured during the first $10 \mathrm{~min}$ of the experiment, was $23.2 \pm 0.3{ }^{\circ} \mathrm{C}$. There was a significantly different response of the two sets of iButtons to the gradual temperature increase of the hot plate and the subsequent instant cold exposure. Upon contact with the hot plate, the iButtons with the top side facing the object were significantly warmer for the first 4 min than those with the bottom side against the object (Fig. 3). During exposure to the cold object the 'top-side' iButtons were significantly cooler during a 5 -min period. We conclude that the top side has a faster response to thermal changes when placed on hard and flat surfaces. The difference between the bottom and top side thermal response may in part have been caused by the locations of the battery (towards the bottom) and the sensor (towards the top).

\section{Validation studies II: Application on human skin}

\subsection{Response time on human skin}

The response time in water has been described above. Since the heat capacity and conductivity of water are higher than those of the

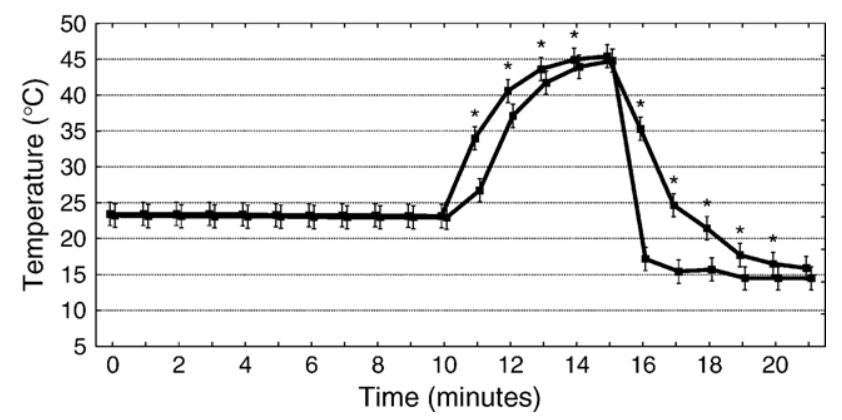

Fig. 3. Mean temperature of 12 iButtons in two experimental conditions. The solid line represents the iButtons that were in contact with the bottom of the bowl with their top side and in contact with the ice with their bottom side. The dotted line represents the iButtons of the opposite condition. At 10 and $15 \mathrm{~min}$ the heat and a cold source were added respectively. ${ }^{*} p<0.05$. The data points were slightly shifted in time to prevent overlap. human skin and only part of the iButton is in direct contact with the skin, it was necessary to validate the iButton for human applications. Therefore, measurements on the human skin were performed. Because local differences can be substantial, the data of mean skin temperature are presented averaged over subjects and 14 body positions and not those of the individual iButton measurements.

\subsubsection{Materials and methods}

Six subjects (three males and three females, mean age: $22.7 \pm$ 1.5 years, mean weight: $67.0 \pm 4.3 \mathrm{~kg}$ ) received information about the nature of the study and signed an informed consent before participating.The temperature obtained by the iButtons (sampling rate one per minute) was compared to that of calibrated thermocouples (ULTRAKUST Electronic GmbH, Germany). According to ISO-standard 9886, skin temperature was measured at four and 14 predefined places by thermocouples and iButtons [11]. ISO 9886 specifies 14 equally weighed body locations to estimate mean skin temperature, but also allows to use only 4 of these sites (neck, scapula, hand and shin) with weighing factors of respectively $0.28,0.28,0.16$ and 0.28 . The devices were fixed onto the skin with adhesive tape (Leukoplast, BSN medical GmbH and Co. KG, Hamburg, Germany). The thermocouples were sampled four times per minute.

Measurements took place in two environmental chambers, one at an ambient temperature of $34.9 \pm 0.1{ }^{\circ} \mathrm{C}$ with a relative humidity of $8.6 \pm 0.5 \%$ and one at a temperature of $15.5 \pm 0.3{ }^{\circ} \mathrm{C}$ and $64.0 \pm 2.3 \%$ relative humidity. $10 \mathrm{~min}$ of exercise were performed before entering the cold chamber at $1.5 \mathrm{~W} / \mathrm{kg}$ body weight on a Lode Excalibur cycle ergometer (Lode, Groningen, The Netherlands).

\subsubsection{Statistical analysis}

The statistical difference between the temperature of the iButtons and that of the thermocouples was tested by means of ANOVA, Tukey's post hoc test [10].

\subsubsection{Results and discussion}

During heating in the hot chamber the iButtons showed significantly lower temperatures from $t=1 \mathrm{~min}$ until $t=14 \mathrm{~min}$ $(p<0.05$, Fig. 4). After 15 min the differences were not significant anymore. In the cold chamber the temperatures of the iButtons were significantly lower during the whole 30 -min interval. The mean temperature difference between the iButtons and thermocouples during both conditions (mean value of all subjects) in the hot chamber was $-0.24 \pm 0.15^{\circ} \mathrm{C}$ (last $10 \mathrm{~min}: 0.17 \pm 0.03^{\circ} \mathrm{C}$ ), and in the cold chamber $0.88 \pm 0.61{ }^{\circ} \mathrm{C}$ (last $10 \mathrm{~min}$ : $0.61 \pm 0.03{ }^{\circ} \mathrm{C}$ ). Thus, the iButtons appear to react slower than thermocouples. The differences were clearly smaller in the hot environment compared to the cold situation. Overall, the mean skin temperature determined using the 14 iButtons differed $0.3 \pm 0.65{ }^{\circ} \mathrm{C}$ from the temperature determined using the 14 thermocouples. The mean skin temperature estimated using four versus 14 thermocouples according to ISO 9886 revealed a difference of $0.4{ }^{\circ} \mathrm{C}$. This indicates that the difference between iButtons and thermocouples is in the same range as the difference between using four or 14 thermocouples to assess skin temperature. 


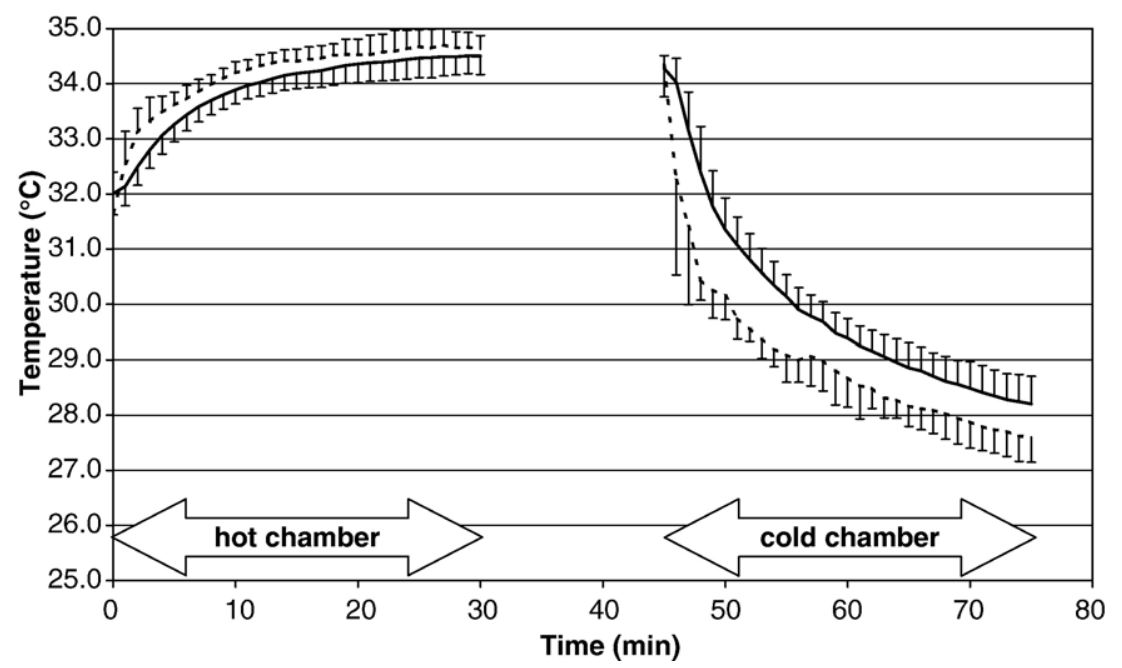

Fig. 4. Temperature plot of the thermocouples (dotted) and iButtons (solid) during the experiment. Vertical bars show the standard deviation. Temperatures between buttons and thermocouples were significantly different $(p<0.05)$, with the exception of temperatures from 15 to $30 \mathrm{~min}$.

The temperature yielded by the thermocouples was closer to ambient temperature than the iButton temperature (Fig. 4). The difference between iButtons and thermocouples was most pronounced in the cold chamber $\left(0.6^{\circ} \mathrm{C}\right)$, where the gradient between ambient temperature and skin temperature was much higher (about $15{ }^{\circ} \mathrm{C}$ ) as compared to the hot chamber (about $\left.2{ }^{\circ} \mathrm{C}\right)$. The effects of the thermal inertia of the iButtons on the temperature response are expected to be visible most clearly when the skin-environment temperature gradient is relatively high. At the end of the experiment the temperatures of the iButtons and thermocouples tended to converge.

Thus, the temperature differences between the thermocouples and iButtons are larger soon after ambient condition changes. The thermal inertia delays the response, and errors up to $1{ }^{\circ} \mathrm{C}$ may occur under realistic circumstances.

\section{Application in field and clinical studies}

\subsection{Sleep and circadian rhythm research}

The diurnal rhythm in core body temperature is one of the most commonly used markers for the phase and amplitude of the endogenous circadian timing system. The 24-h rhythm in core body temperature is the result of differential 24-h rhythms in heat production and heat loss. It has been demonstrated that under strictly controlled so-called 'constant routine' conditions, in which subjects remain awake in a fixed semi-supine condition without physical activity and with food and drinks taken in small portions throughout the day and night, the core temperature rhythm remains. Furthermore, the core temperature rhythm has been shown to result mostly from the circadian rhythm in heat loss, and to a lesser extent from changes in heat production [12]. Dry heat loss is caused by increased skin blood flow, allowing the dissipation of heat from the warm blood to the cooler environment. Although the iButton is not suitable for core body temperature assessment in humans, the assessment of temperature at multiple sites of the skin provides a reliable estimate of heat loss [12,13], suggesting a role for the iButton in long-term studies on the circadian variation in skin temperature and heat-loss which is responsible for an important part of the circadian variation in core body temperature.

The value of skin temperature assessment extends to sleep research, because endogenous skin warming, which results from increased skin blood flow, is functionally linked to sleep propensity. In addition, exogenous skin warming in the thermoneutral, comfortable range has a strong impact on sleep propensity $[7,14,15]$.

Therefore, the feasibility of using multiple iButtons in skin temperature studies on circadian rhythms and sleep performed outside the laboratory was investigated. The aim of the first study was to obtain diurnal rhythms in proximal and distal skin temperature under natural living conditions. The aim of the second study was to obtain proximal and distal skin temperature during standard multiple sleep latency tests (MSLTs) in a clinical setting.

\subsubsection{Materials and methods}

For both studies, the bottom side of nine iButtons was fixed onto the skin in both proximal and distal areas using Fixomul tape (Beiersdorf, Hamburg, Germany). These locations were used because for long-term recordings the slightly larger area of the flat side gives a better fixation when taped onto the skin. At the time of recording, it had not yet been evaluated that the top side had a faster response time. Apart from the iButton, the subjects wore an Actiwatch (Cambridge Neurotechnology Ltd., Cambridge, UK) on the non-dominant wrist for a continuous recording of physical activity.

Proximal skin temperature was measured at five places, i.e. the left and right mid-thigh on the musculus rectus femoris, the right and left infraclavicular area, and the abdomen $(1 \mathrm{~cm}$ above the navel). Distal skin temperature was measured at four points: the thenar area at the palmar sites of the left and right hand, and the medial metatarsal area at the plantar sites of the left and right foot. Average distal skin temperature $\left(T_{\text {dist }}\right)$ was calculated as the average of the average temperature of both feet and the 
average temperature of both hands. A weighted average was calculated for proximal skin temperature $($ prox $=0.383 *$ average (mid-thighs) $+0.293 *$ average (infraclavicular sites) + $0.324 *$ abdomen) according to a modification of the method used by Kräuchi et al. [16]. The first study was aimed at obtaining three full 24-h cycles. Consequently, a sample rate of once every $3 \mathrm{~min}$ was selected. This allowed for the assessment of four full 24-h cycles, whereas a sample rate of once every 2 min just fell short of sampling three full cycles. The second study was aimed at obtaining a single day and was performed with a sample rate of once every minute.

In contrast to most laboratory assessments, it seldom happens that field assessments are free of artefacts. Therefore an automated artefact rejection procedure was applied to exclude extreme drops and rises in temperature. Because of the bimodal rather than normal distribution of the temperature data, no artefact rejection was applied to exclude data more than two or three standard deviations from the mean, but rather a three-step nonparametric
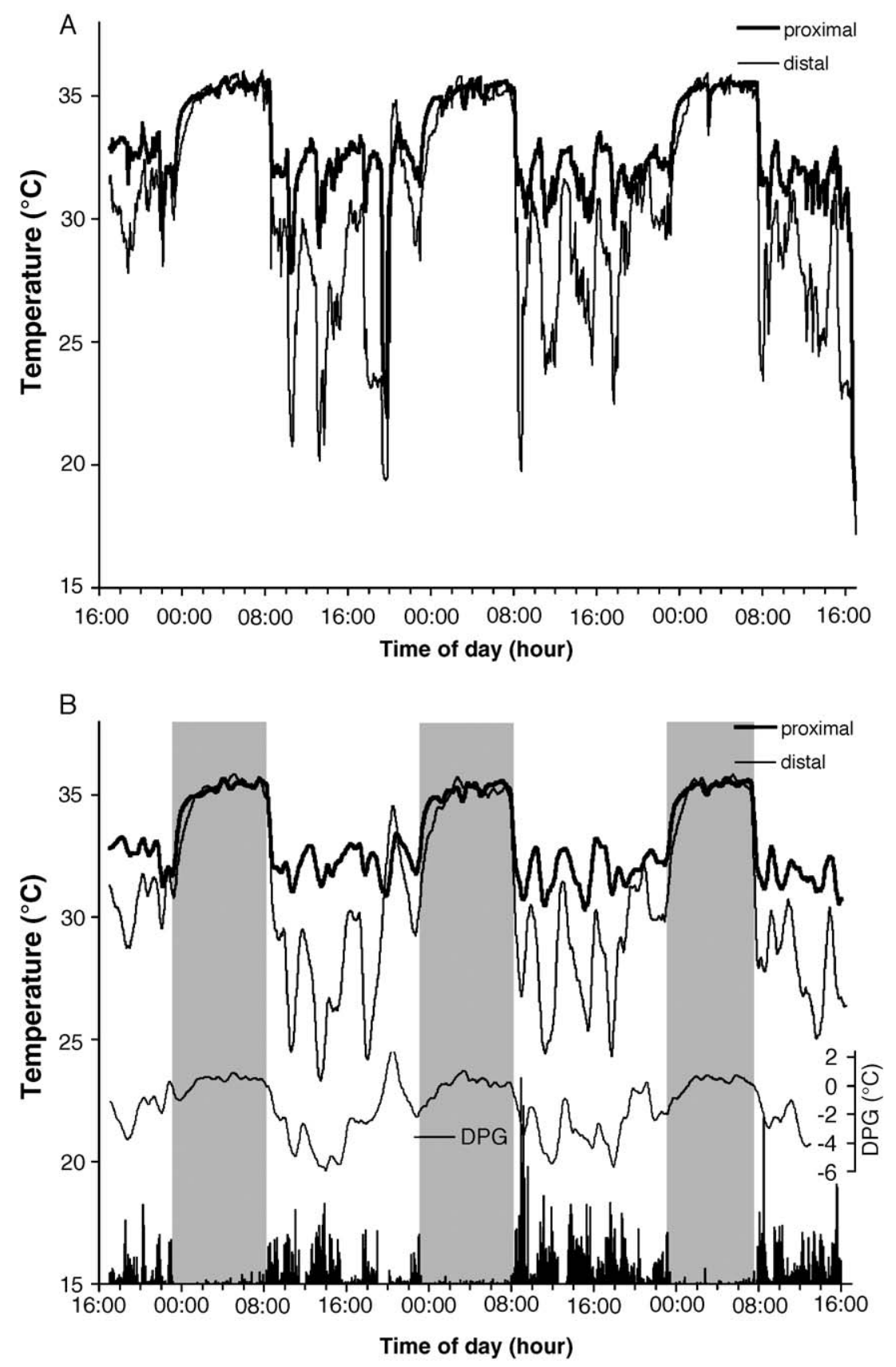

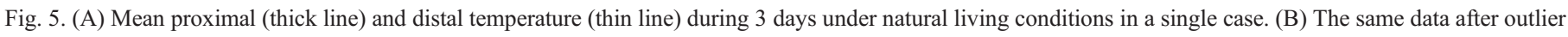

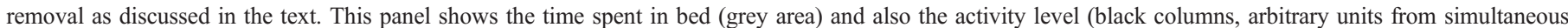

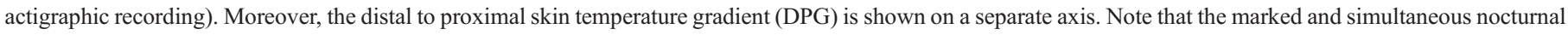

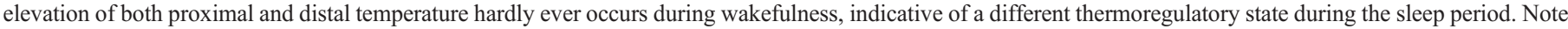

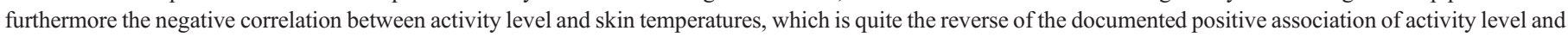
core body temperature. 
method. Firstly, the rate of change (ROC) of all subsequent single channel data points was calculated, their quartiles $Q_{25}$ and $Q_{75}$, and their interquartile distance $\left(\mathrm{IQR}_{\mathrm{ROC}}\right)$. Any data point with a rate of change exceeding 1 time the interquartile distance from $Q_{25}$ or $Q_{75}$ was removed. This step resulted in the rejection of very fast drops or increases in temperature. Secondly, in the resulting restricted raw data, the quartiles $Q_{25}$ and $Q_{75}$ and their interquartile distance $\left(\mathrm{IQR}_{\mathrm{LEVEL}}\right)$ were calculated. Any data point with a level exceeding 1 time the interquartile distance from $Q_{25}$ or $Q_{75}$ was removed. This step resulted in the rejection of very low temperatures. Thirdly, the resulting gaps in the single channels were interpolated linearly followed by an 11-point rectangular smoothing.

\subsubsection{Results and discussion}

Two single cases are discussed here to illustrate the feasibility and usefulness of multiple-site iButton skin temperature measurements in field studies on circadian rhythms and sleep. Fig. 5A shows three 24-h cycles of average proximal and distal skin temperature in an unmedicated male subject, aged 59, with subjective sleep complaints under natural living conditions. Although the raw data already showed a clear 24-h rhythm, some of the daytime variation may have been due to artefacts caused by poor skin contact as a result of loose tape or, e.g., dishwashing. As shown in Fig. 5B, the three-step artefact rejection procedure resulted in far fewer noisy distal and proximal curves, whereas the variability was maintained.

During daytime, the distal skin temperature (thin line) hardly ever exceeded proximal skin temperature. The diverging decrease in proximal skin temperature and the increase in distal skin temperature reported under laboratory conditions did not occur systematically under habitual living circumstances [17], underscoring the value of unrestrained iButton recordings for our insight into the physiology of diurnal temperature variation. Under constant routine laboratory conditions, activity levels were minimal. Under the present unrestricted conditions, clear correlations between skin temperature and previous activity levels were observed. The correlation between activity level and distal skin temperature was strongest at a lag of $9 \min$ ( $r=-0.52$ for all data, -0.32 for out-ofbed data only). The correlation between activity level and proximal skin temperature was strongest at a lag of $12 \min (r=-0.56$ for all data, -0.50 for out-of-bed data only). The correlation between activity level and core temperature was less pronounced, but strongest at a lag of $30 \mathrm{~min}(r=+0.11$ for all data, +0.08 for out-ofbed data only). Thus, in addition to the well-known positive correlation between activity and core body temperature, we were able to demonstrate that there is a negative correlation between activity level and skin temperature in everyday life.

During nighttime, both distal and proximal temperature reached a level not seen during wakefulness. They also showed very little variability due to the fixed supine position, lack of activity and a bed microclimate of about $34^{\circ} \mathrm{C}$ [18]. Thus, the diurnal rhythms of proximal and distal skin temperature under natural conditions were in phase, with the optimal levels of both occurring during the night. Note that this finding is in contrast with constant routine studies in which subjects were not allowed to sleep and were exposed to an environmental temperature much lower than that of the habitual nocturnal microclimate. Under such laboratory conditions, the distal skin temperature increased likewise, but the proximal skin temperature decreased instead of increasing during the night [12]. In lab studies in which sleep was allowed, the nocturnal increases in distal and proximal temperature were still not as pronounced throughout the night as those of the present recordings under natural living conditions [17]. It may be that subjects sleeping under a light cover at $22{ }^{\circ} \mathrm{C}$ laboratory temperature may not attain the microclimate of about $34{ }^{\circ} \mathrm{C}$ that is usually found with normal bedding. This example once more underscores the importance of ambulatory recordings in addition to laboratory studies to provide complete insight into everyday physiological processes.

The second case illustrates the application of iButtons in clinical sleep investigation. Because under controlled conditions the gradient of distal minus proximal skin temperature (DPG) has been shown to be one of the best physiological predictors of sleep propensity [2], it might be relevant to include skin temperature measurements in, e.g., the multiple sleep latency test (MSLT). The MSLT is widely used in sleep clinics to evaluate whether daytime sleepiness is associated with pathological conditions such as sleep apnea and narcolepsy. An MSLT consists of four or five 20-min periods at fixed time intervals during which the subject lies in bed in a darkened room, while trying to fall asleep. Polysomnography is used to determine sleep onset latency. Fig. 6 shows the DPG (proximal and distal assessed from multiple sites as described above) in two healthy male subjects aged 31 (case 1) and 34 (case 2) as obtained during an MSLT. The DPG is shown from $30 \mathrm{~min}$ prior to lights out until the end of the 20 -min lights out period. Note that the DPG of Case 1 is near zero, indicative of distal temperatures that are nearly similar to the proximal temperatures in this case. The DPG of Case 2 is negative, indicative of distal temperatures 3 to $4{ }^{\circ} \mathrm{C}$ lower than the proximal temperatures. The average sleep onset latency of Case 1 was $4.9 \pm 1.3$ min (mean \pm S.E.M.) versus $8.4 \pm 1.2 \mathrm{~min}$ in Case 2. This example matches the earlier laboratory findings of faster sleep onsets associated with higher DPG [2], and suggests that skin temperature assessment is of value not only in the laboratory but also within the setting of clinical sleep evaluations.

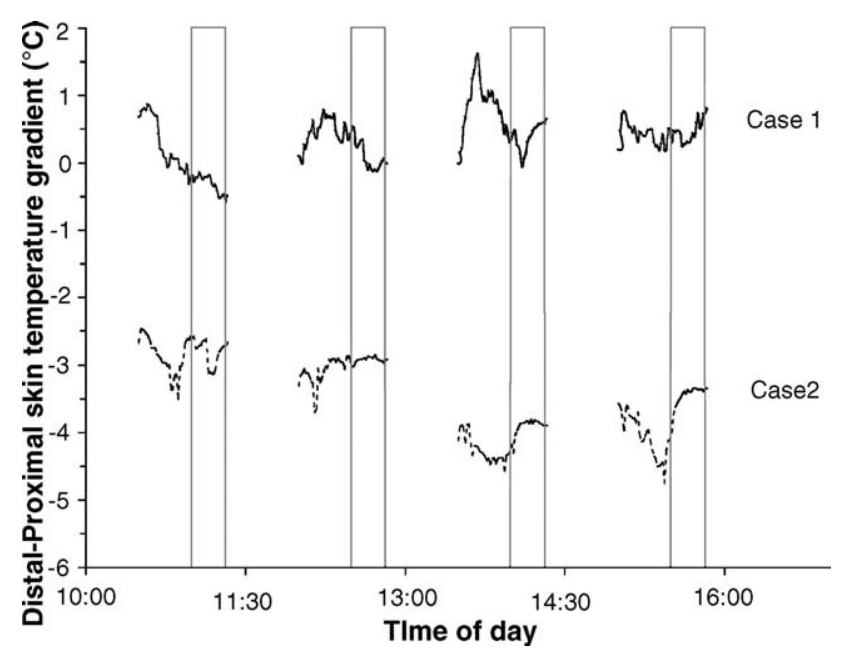

Fig. 6. Distal minus proximal skin temperatures in two cases evaluated in a multiple sleep latency protocol. See text for details. 
Whereas the first study example indicates considerable differences between laboratory and field studies in skin temperature physiology, the second example suggests generalizability of laboratory findings to clinical settings, underscoring the value of extending laboratory studies to field studies which have become much more feasible using the present method of wireless monitoring.

\subsection{Hypothermia during cardiac surgery}

For over four decades, the whole body hypothermia has been used widely to reduce metabolic demand and protect vital organs during open heart surgery. During cardiopulmonary bypass surgery, cooling can be achieved using the heart lung machine (HLM). Afterwards the body is rewarmed followed by decoupling of the HLM. However, due to unnatural distribution of body heat (relatively cold periphery) often an undesirable drop of core temperature occurs [19]. This afterdrop adversely affects recovery. Simultaneous measurements of temperature distribution and blood flow provide more insight in the occurrence and prevention of afterdrop. Here we present the use of iButtons in a study on hypothermia and rewarming during cardiac surgery.

\subsubsection{Materials}

This case study is of an 78-year-old female patient. The results of an interval of $250 \mathrm{~min}$ are shown. At time point $T=0$ anesthetics were supplied. 95 min later cooling was initiated using the HLM. At $T=125$, rewarming started, again using the HLM, and at $T=198$ the HLM was disconnected.

Skin temperatures were measured by means of iButtons. Only the skin temperature of the lower arm and fingertip are presented here. Core temperatures were recorded from the nasopharynx (Philips, The Netherlands).

\subsubsection{Results and discussion}

Fig. 7 shows the main temperature characteristics. Upon cooling with the HLM the core temperature dropped, followed

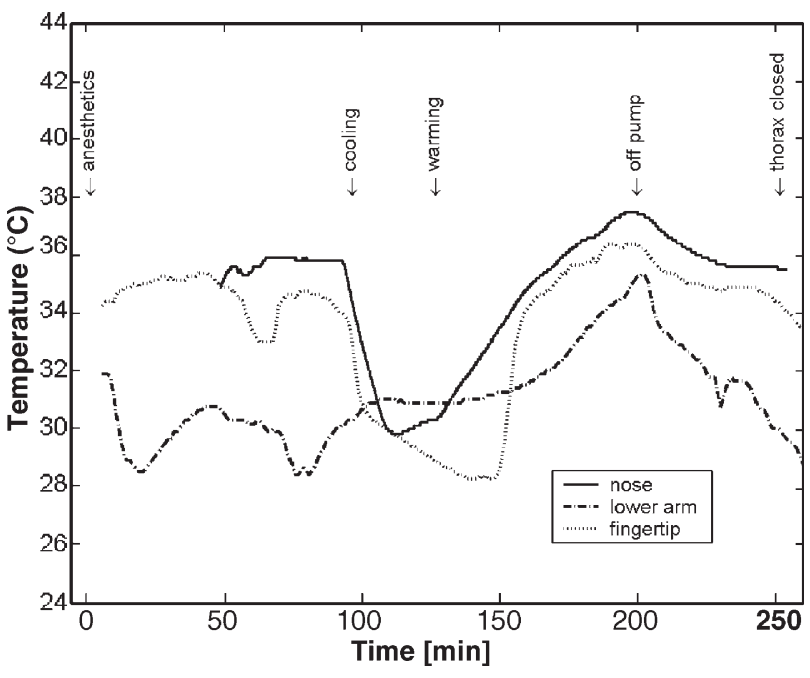

Fig. 7. The course of skin temperature (lower arm and finger tip) and core temperature (nasopharynx) during cardiac surgery and rewarming. For explanation see text. by a drop in temperature of the fingertip. When rewarming with the HLM the core temperature gradually increased. After a delay, the fingertip temperature also increased. During the offpump situation peripheral temperatures dropped again. Moreover, an afterdrop of the core temperature was evident. The varying changes between fingertip and underarm reflect changes in the skin blood flow [13], which is low during cooling, then suddenly rises during the rewarming period. There was also a drop in the patient's skin temperature during recovery.

The advantage of using iButtons in this situation is that they are easy to sterilize and wireless, and thus do not hinder the surgical procedure. More iButtons may be used in order to map the temperature distribution of the skin. A disadvantage could be the time delay when absolute temperatures are required at a certain time point. The information obtained from iButtons is especially useful for research purposes during surgery. If online measurements are required, the iButtons should not be used.

\section{Conclusions}

We have described the accuracy, time response and usefulness of iButtons for measuring human skin temperature. The main advantages are that the iButtons are wireless, suitable for long measurement periods, sturdy, and easy to sterilize. The software is user-friendly. This means their field of application is large.

The main disadvantages are, depending on the purpose of the study, that the maximum sampling rate is one per minute, the relatively large size compared to most sensor tips (disregarding their wires), the large time constant, and the inability of the validated type to measure below $15^{\circ} \mathrm{C}$.

The validation study demonstrated that all of the 30 iButtons tested performed better than the specifications (accuracy $1{ }^{\circ} \mathrm{C}$ ) provided by the firm. We observed an average accuracy of $-0.09{ }^{\circ} \mathrm{C}$, with one sensor showing a maximum deviation of $-0.4{ }^{\circ} \mathrm{C}$. We showed that this accuracy can be improved by using individual calibration regressions. However, it should be noted that this correction method may not always be available. It is complex because of the high demands on the specifications of the calibration bath and reference thermometer.

The response time is relatively long, i.e. a $\tau$ value of $19 \mathrm{~s}$. Thermocouples perform much better in this respect, with $\tau$ values usually less than $1 \mathrm{~s}$. Whether fast responses are required depends on the type of experiment. In our test on the human skin we showed that because of the thermal inertia the errors reach $1{ }^{\circ} \mathrm{C}$. In case of faster fluctuations in skin temperature even larger errors are to be expected. On the other hand, in the sleep and circadian studies the response time appears of negligible importance. The case studies that were described demonstrate the usefulness in field situations and in laboratory and clinical settings. Many other applications are possible. As with all measuring devices, the specifications of the measuring device should be checked beforehand against the accuracy required for the experiments. The major advantage of iButton use is that it allows multiple skin site measurements in those situations in which wired instruments are unpractical, as in long-term field studies and in poorly complying subjects. In some cases, for example in poorly complying demented subjects, the evaluation of skin thermophysiology may in fact only become 
possible using iButtons. Finally, we showed that field measurements may either confirm or diverge from laboratory findings, in both cases contributing considerably to our understanding of thermophysiology and its relevance during everyday life.

\section{Acknowledgements}

The authors acknowledge the contributions of Rob Wüst, Aukje de Vrijer, Eline van Es, Jaike de Graaf and Floor Hettinga.

\section{References}

[1] Davidson AJ, Aujard F, London B, Menaker M, Block GD. Thermochron iButtons: an inexpensive method for long-term recording of core body temperature in untethered animals. J Biol Rhythms 2003;18(5):430-2.

[2] Kräuchi K, Cajochen C, Werth E, Wirz-Justice A. Warm feet promote the rapid onset of sleep. Nature 1999;401(6748):36-7.

[3] Marken Lichtenbelt WDv, Westerterp-Plantenga MS, Van Hoydonk P. Individual variation in the relation between body temperature and energy expenditure in response to elevated ambient temperature. Physiol Behav 2001;73:235-42.

[4] Marken Lichtenbelt WDv, Schrauwen P, Kerckhove Svd, WesterterpPlantenga MS. Individual variation in body temperature and energy expenditure in response to mild cold. Am J Physiol 2002;282:E1077-83.

[5] Mzilikazi N, Lovegrove BG, Masters JC. No evidence for torpor in a small African mainland primate: the Lesser Bushbaby, Galago moholi. In: Barnes BM, Carey HV, editors. Life in the cold. Evolution, mechanisms, adaptation, and application. University of Alaska Fairbanks; 2004. p. 29-40.

[6] Taylor EN, DeNardo DF, Malawy MA. A comparison between point- and semi-continuous sampling for assessing body temperature in a free-ranging ectotherm. J Therm Biol 2004;26(2):91-6.

[7] Raymann RJ, Swaab DF, Van Someren EJ. Cutaneous warming promotes sleep onset. Am J Physiol Regul Integr Comp Physiol 2005;288(6):R1589-97.
[8] Daanen H, van Es E, Graaf J. Heat strain and gross efficiency during endurance exercise after lower, upper, or whole body precooling in the heat. Int J Sports Med 2005;26:1-10.

[9] Altman DG, Bland JM. Measurement in medicine: the analysis of method comparison studies. Statistician 1983;32:307-17.

[10] StatSoft I: STATISTICA data analysis software system. Edn version 6 . Edited by. Tulsa; 2003.

[11] ISO9886: Evaluation of thermal strain by physiological measurements. Edited by. Geneva: ISO; 2000.

[12] Kräuchi K, Wirz-Justice A. Circadian rhythm of heat production, heart rate, and skin and core temperature under unmasking conditions in men. Am J Physiol 1994;267(3 Part 2):R819-29.

[13] Rubinstein E, Sessler D. Skin-surface temperature gradients correlate with fingertip blood flow in humans. Anesthesiology 1990;73:541-5.

[14] Van Someren EJW. Sleep propensity is modulated by circadian and behavior-induced changes in cutaneous temperature. J Therm Biol 2004;29:437-44.

[15] Van Someren EJW. More than a marker: interaction between the circadian regulation of temperature and sleep, age-related changes, and treatment possibilities. Chronobiol Int 2000;17:313-54.

[16] Kräuchi K, Cajochen C, Mori D, Graw P, Wirz-Justice A. Early evening melatonin and S-20098 advance circadian phase and nocturnal regulation of core body temperature. Am J Physiol 1997;272(4 Pt 2):R1178-88.

[17] Kräuchi K. How is the circadian rhythm of core body temperature regulated. Clin Auton Res 2002;12:147-9.

[18] Van Someren EJ, Raymann RJ, Scherder EJ, Daanen HA, Swaab DF. Circadian and age-related modulation of thermoreception and temperature regulation: mechanisms and functional implications. Ageing Res Rev 2002;1(4):721-78.

[19] Rajek A, Lenhardt R, Sessler DI, Grabenwoger M, Kastner J, Mares P. et. al. Tissue heat content and distribution during and after cardiopulmonary bypass at 17 degrees C. Anesth Analg 1999;88(6):1220-5. 